\title{
PREPARATION AND EVALUATION OF METOLAZONE SOLID DISPERSIONS AND FAST DISSOLVING TABLETS USING STERCULIA FOETIDA SEED STARCH AND PLASDONE K-29/32 AS SUPERDISINTEGRANTS
}

\author{
SANDEEP DOPPALAPUDI*, VIDYADHARA SURYADEVARA
}

*Chebrolu Hanumaiah Institute of Pharmaceutical Sciences, Chandramoulipuram, Chowdavaram, Guntur, Andhra Pradesh, India - 522019, University College of Pharmaceutical Sciences, Acharya Nagarjuna University, Nagarjuna Nagar, Guntur - 522510

Email: pharmacydeepu@gmail.com

Received: 20 Apr 2020, Revised and Accepted: 20 May 2020

\section{ABSTRACT}

Objective: The objective of the current study is to improve the solubility of the Biopharmaceutical Classification System (BCS) Class-II drug, Metolazone, using various superdisintegrants.

Methods: Starches were extracted from Sterculia foetida seed powder by water and alkali techniques i.e., sodium hydroxide at $0.1 \%$, $0.25 \%$ and $0.5 \%$ concentrations. Several phytochemical and physicochemical parameters were evaluated on the extracted starches. Solid dispersions of Metolazone were prepared by the solvent evaporation technique using plasdone K-29/32 alone and by mixing plasdone K-29/32 with Sterculia foetida seed starch. Various physical parameters were evaluated for the prepared solid dispersions. Tablets were prepared using Metolazone solid dispersions and varying concentrations of Sterculia foetida seed starch by direct compression technique. Pre and post-compression parameters were evaluated along with in vitro drug release studies, characterization using Scanning Electron Microscopy (SEM) and stability studies.

Results: Phytochemical tests showed the presence of starch in all extracts. Starch prepared from 0.1\% sodium hydroxide (SFS2) showed best physicochemical properties. In vitro dissolution studies revealed that solid dispersion MS4 containing Metolazone and plasdone K-29/32 in 1:3 ratios showed better drug release. Formulation MPT6 containing MS5 solid dispersion with 15\% w/w of SFS2 showed enhanced drug release. SEM studies revealed no major interactions between drugs and excipients. Accelerated stability studies showed that all tablets were stable.

Conclusion: Sterculia foetida seed starch and plasdone K-29/32 have enhanced the solubility of Metolazone.

Keywords: Metolazone, Solid dispersions, Plasdone K-29/32, Sterculia foetida, Fast dissolving tablets

(C) 2020 The Authors. Published by Innovare Academic Sciences Pvt Ltd. This is an open access article under the CC BY license (http://creativecommons.org/licenses/by/4.0/) DOI: http://dx.doi.org/10.22159/ijap.2020v12i4.37975. Journal homepage: https://innovareacademics.in/journals/index.php/ijap

\section{INTRODUCTION}

Solubility of drugs is an important pre-requisite in eliciting their pharmacological effect in the body. Most of the drugs are facing the problem of aqueous solubility. Enhancement of solubility of such drugs can be helpful for many patients. It is highly beneficial for geriatrics and paediatrics that prefer to take drugs through oral route [1]. The solubility can be enhanced by various techniques like preparation of solid dispersions, cyclodextrins, liposomes and fast-dissolving tablets. They change the properties of drugs and make them more soluble in water [2]. Solid dispersions are the dosage forms which have two main components; one is a hydrophobic drug and other a hydrophilic carrier. They were prepared by various techniques like physical mixing, solvent evaporation and fusion techniques [3]. Solid dispersions adopt many techniques to dissolve drug in water like making complexes, reducing the particle size, increasing wetting time etc [4].

Fast dissolving tablets (FDTs) are the formulations which releases the drugs immediately after taking into the mouth within seconds to 3 min. They contain special types of ingredients called superdisintegrants [5]. FDTs were formulated using different techniques like direct compression, wet granulation, lyophilization etc. Superdisintegrants are the agents which make the drug disintegrate rapidly in water by wicking or swelling or by any other mechanisms [6]. Till now, several synthetic and semi-synthetic superdisintegrants have been used in the preparation of dosage forms. Recent studies have suggested that usage of natural agents as superdisintegrants is beneficial [7]. Natural sources are gaining attention in the development of pharmaceuticals nowadays. Among those, starches stand on top because of their varying applications in the development of pharmaceutical formulations. Starches were used as binders, bulking agents and superdisintegrants [8].

In the current study, an attempt was made to extract starch from of Sterculia foetida seed powder and to use it as superdisintegrant for formulating fast-dissolving tablets. Sterculia foetida belongs to the family Malvaceae, grows in climates of India, Philippines and Indonesia. Their seeds have a black coat which can be easily removed. The central part contains the cotyledons. They contain starch and various significant phytochemical constituents [9]. Metolazone, which is a diuretic agent was selected for the present study. It is a BCS (Biopharmaceutical Classification System) class-II drug which is poorly soluble in water. It shows the diuretic effect by inhibiting the sodium-chloride symporter pump which is present in distal convoluted tubule of nephron. This it prevents the reabsorption of sodium, which favours its excretion [10]. Along with sodium, water also gets excreted from body. This is highly beneficial in case of hypertensive patients who have water retention as major obstruction. The bioavailability of metolazone is approximately $65 \%$. Only $33 \%$ of the drug is bound to plasma proteins. It has an approximate elimination half-life of $14 \mathrm{~h}$. Based on pharmacokinetic and pharmacodynamic parameters, Metolazone is selected as drug of choice for present study.

\section{MATERIALS AND METHODS}

\section{Materials}

Metolazone and croscarmellose sodium were gift samples from M/s. NATCO Pharma Ltd. (Hyderabad, India). Plasdone K-29/32 and microcrystalline cellulose were gift samples from Pellets Pharma Ltd (Hyderabad, India). Sodium hydroxide, saccharin sodium, magnesium stearate and talc were procured form S. D Fine Chem. Ltd. (Mumbai, India). Sterculia foetida seeds were procured from the local market (Tirumala, Andhra Pradesh, India) and were identified and authentified by Dr. K. Ammani, Professor, Department of Botany, Acharya Nagarjuna University, Guntur and a voucher specimen (01/2017) was preserved in the Department of Pharmaceutics, Chebrolu Hanumaiah Institute of Pharmaceutical Sciences, Chowdavaram, Guntur, India. 


\section{Extraction of starch from Sterculia foetida seeds}

Sterculia foetida seed starch was isolated using aqueous and alkali extraction methods [11]. 5g Sterculia foetida seed flour was added into $100 \mathrm{ml}$ distilled water, $0.1 \%, 0.25 \%$ and $0.5 \%$ sodium hydroxide solutions separately and soaked ( $6 \mathrm{~h}$ and $8 \mathrm{~h})$ at room temperature then stirred constantly. The slurry was filtered through 212 mesh stainless sieve and remaining sediment was washed with distilled water for three times. The filtrates were combined and precipitated overnight at $4{ }^{\circ} \mathrm{C}$. The supernatant was discarded and the crude starch was cleaned with distilled water. This step was repeated three times and starch cake was dried at $40{ }^{\circ} \mathrm{C}$ for $24 \mathrm{~h}$ in oven dryer. The starch was ground with a mortar and pestle. The starches were packed in a plastic bag and stored at room temperature.

\section{Phytochemical tests for Sterculia foetida seed powder and extracted starches}

The raw Sterculia foetida seed powder and starches extracted were subjected to various phytochemical tests for the identification of carbohydrates, proteins, alkaloids, glycosides, steroids, flavonoids and saponins [12]. The results were indicated in table 1.

\section{Evaluation of physicochemical properties of Sterculia foetida seed powder and extracted starches}

Various physicochemical properties like gelatinization temperature, $\mathrm{pH}$, viscosity, swelling index, water absorption index, total microbial load, acidity, fluorescence, presence of oxidizing substances, sulphated ash, loss on drying and amylose content were evaluated using suitable methods [13].

\section{Acidity}

One gram of starch was added to $100 \mathrm{ml}$ of ethanol (70\%), which was previously neutralized to phenolphthalein solution. This solution was shaken for $1 \mathrm{~h}$, filtered and $50 \mathrm{ml}$ of the filtrate was titrated with $0.1 \mathrm{M}$ sodium hydroxide.

\section{Fluorescence}

$500 \mathrm{mg}$ of starch powder was dissolved in organic solvent, placed on a glass slide and was examined under UV cabinet for the presence of any fluorescent material.

\section{Oxidizing substances}

To $0.5 \mathrm{~g}$ of the sample, $10 \mathrm{ml}$ of water and $1 \mathrm{ml}$ of acetic acid were added and stirred until a homogeneous suspension was obtained. $0.5 \mathrm{ml}$ of a freshly prepared saturated solution of potassium iodide was added, mixed and allowed to stand for $5 \mathrm{~min}$. Non-production of blue or blue colour indicates the absence of oxidizing substances.

\section{Sulphated ash}

1-2 g of the starch was placed in an accurately weighed crucible, ignited and thoroughly charred. Then it is cooled and the residue was moistened with $1 \mathrm{ml}$ of sulphuric acid. It was heated gently until white fumes are no longer evolved and ignited at $800{ }^{\circ} \mathrm{C}$ until black particles have disappeared. The crucible was cooled and few drops of sulphuric acid was added and heated. Then it was weighed. This procedure was repeated until two successive weighing doesn't differ by more than $0.5 \mathrm{mg}$.

\section{Loss on drying}

Loss on drying is widely used to determine the moisture content of a sample, although occasionally it may refer to the loss of any volatile matter from the sample. Not more than 15\% (for all starches except potato starch) and not more than $20 \%$ (for potato starch) of weight loss should be obtained. It was determined by drying $0.2 \mathrm{~g}$ of starch in an oven at $105^{\circ} \mathrm{C}$.

\section{Test for amylose content}

To $100 \mathrm{mg}$ of starch, $1 \mathrm{ml}$ of ethanol and $9 \mathrm{ml}$ of $1 \mathrm{~N}$ sodium hydroxide were added and kept aside for overnight. The suspension was thoroughly mixed. The dispersed sample was transferred to a $100 \mathrm{ml}$ volumetric flask and diluted to the mark with distilled water. $5 \mathrm{ml}$ of this solution was pipetted into a $100 \mathrm{ml}$ volumetric flask, 1 $\mathrm{ml}$ of $1 \mathrm{~N}$ glacial acetic acid and $2 \mathrm{ml}$ of Iodine solution $(0.02 \mathrm{~N})$ were added. The volume was made up to $100 \mathrm{ml}$ with distilled water and the absorbance was measured at $620 \mathrm{~nm}$.

\section{Preparation of metolazone solid dispersions by solvent evaporation method}

Solid dispersions of Metolazone were prepared using plasdone K29/32 in different ratios by solvent evaporation method [14]. Measured quantities of Metolazone and Plasdone K-29/32 were placed in a china dish, few $\mathrm{ml}$ of methanol was added and heated at low temperature until both gets melted. The mixture was allowed to evaporate by stirring. The solid mass was obtained after the solvent gets evaporated. The granules obtained were crushed and stored in desiccator for further studies. The results were given in table 3 .

\section{Evaluation of physical parameters}

The prepared solid dispersions were evaluated for various physical parameters such as angle of repose, Carr's index, Hausner's ratio, particle size and drug content [15]. The results were indicated in table 4.

\section{In vitro dissolution studies}

Dissolution studies for all solid dispersions were performed in a calibrated dissolution test apparatus (LABINDIA DS8000) equipped with paddles employing $900 \mathrm{ml}$ of phosphate buffer $\mathrm{pH} 6.8$ as dissolution medium. The paddles were operated at $75 \mathrm{rpm}$ and temperature was maintained at $37 \pm 1{ }^{\circ} \mathrm{C}$ throughout the experiment. The samples were withdrawn at 5, 10, 15, 20 and $30 \mathrm{~min}$ and replaced with equal volume of same dissolution medium to maintain the sink conditions. The amount of the drug dissolved in the dispersions was estimated by double-beam $\mathrm{U}$. V spectrophotometer at $237 \mathrm{~nm}$. The dissolution profiles were indicated in fig. 1 .

\section{Preparation of metolazone tablets}

Metolazone tablets were prepared by direct compression technique using the solid dispersion, which showed maximum drug release. Sterculia foetida seed starch with the best physicochemical properties was selected as superdisintegrant for the preparation of tablets. The efficiency of starch was compared with croscarmellose sodium. The solid dispersion concentration was maintained constant, while the superdisintegrants concentration was increased. The raw materials were individually weighed and transferred to mortar. Using pestle, the components were mixed well and the prepared granules were passed through sieve no. 40. The granules were taken into a plastic bag and lubricated with talc and magnesium stearate. Then they were compressed as tablets under identical conditions. The compositions of various tablet formulations were given in table 5 .

\section{Evaluation of pre-compression parameters}

The prepared granules were evaluated for pre-compression parameters such as angle of repose, Carr's index and Hausner's ratio [16]. The results were given in table 6 .

\section{Evaluation of post-compression parameters}

The compressed tablets were further evaluated for postcompression parameters such as weight uniformity, hardness, friability, wetting time, dispersion test and drug content [17]. The results were given in table 7 .

\section{In vitro dissolution studies of metolazone tablets}

Dissolution studies for Metolazone tablet formulations were performed in a calibrated dissolution test apparatus (USP apparatus II method) using $900 \mathrm{ml}$ of phosphate buffer $\mathrm{pH} 6.8$ as dissolution medium. The paddles were operated at $75 \mathrm{rpm}$ and temperature was maintained at $37 \pm 1{ }^{\circ} \mathrm{C}$ throughout the experiment. Samples were withdrawn at 5,10 , 15,20 and $30 \mathrm{~min}$ and replaced with an equal volume of same dissolution medium to maintain the constant conditions. The amount of drug dissolved was estimated using $\mathrm{U}$. V spectrophotometer at $237 \mathrm{~nm}$. The dissolution profiles were given in fig. 2 and 3.

\section{Characterization studies}

Based on dissolution studies, the optimized formulations were subjected to scanning electron microscopy (SEM) analysis to know surface characteristics. The results were shown in fig. 4. 


\section{Accelerated stability studies}

Accelerated stability studies were carried out on optimized formulations as per International Council for Harmonisation of Technical Requirements for Registration of Pharmaceuticals for Human Use (ICH) guidelines. These studies were carried out to investigate the effect of temperature on the physical properties and drug release of the tablets [18]. The results were given in table 8 . The optimized tablets were also evaluated for in vitro drug release studies and indicated in fig. 5 and 6.

\section{RESULTS AND DISCUSSION}

\section{Extraction of starch from Sterculia foetida seeds}

The starches extracted from Sterculia foetida seed powder were white to creamish, with mild granules, free-flowing and stable in nature.

Phytochemical screening of Sterculia foetida seed flour and starch extracts

The raw Sterculia foetida seed powder and starches extracted were subjected to phytochemical screening. The results were indicated in table 1.

\section{Physicochemical parameters of Sterculia foetida seed flour and} starch extracts

Physicochemical parameters were evaluated for all the starches. The results were indicated in table 2 . The starch SFS2 showed high swelling index and water absorption index which made it suitable for selection of solid dispersions and tablets.

\section{Preparation of metolazone solid dispersions by solvent evaporation method}

Solid dispersions of Metolazone were prepared using plasdone K$29 / 32$ as carrier in different ratios by the solvent evaporation method. The composition was given the table 3 .

\section{Evaluation of physical parameters}

Various physical parameters for Metolazone solid dispersions were evaluated. All the parameters were found to be within I. P specified limits. The pure drug Metolazone is indicated as MP. The obtained results were indicated in table 4.

\section{In vitro dissolution studies of metolazone solid dispersions}

Formulation MS4, prepared in 1:3 ratios of Metolazone and plans done K-29/32 showed maximum drug release proving that solid dispersions prepared by the solvent evaporation technique increases drug release. Usage of superdisintegrants has proved to increase dissolution efficiency $[19,20]$. Past studies suggest that solvent evaporation technique has proved to be successful in preparation of solid dispersions for solubility enhancement [21, 22]. The dissolution profiles of Metolazone solid dispersions were given in fig. 1.

Table 1: Phytochemical screening of Sterculia foetida seed powder and starches (+indicates present; -indicates absent)

\begin{tabular}{|c|c|c|c|c|c|}
\hline Test & SFSP & SFS1 & SFS2 & SFS3 & SFS4 \\
\hline Carbohydrates & + & + & + & + & + \\
\hline Polysaccharides & + & + & + & + & + \\
\hline Proteins & - & - & - & - & - \\
\hline Alkaloids & + & - & - & - & - \\
\hline Glycosides & - & - & - & - & - \\
\hline Steroids & - & - & - & - & - \\
\hline Flavonoids & + & - & - & - & - \\
\hline Saponins & + & - & - & - & - \\
\hline
\end{tabular}

Table 2: Physico-chemical properties of Sterculia foetida seed powder and starches

\begin{tabular}{|c|c|c|c|c|c|}
\hline Properties & SFSP & SFS1 & SFS2 & SFS3 & SFS4 \\
\hline Gelatinization temperature & $194-200{ }^{\circ} \mathrm{C}$ & $221-230^{\circ} \mathrm{C}$ & $232-240{ }^{\circ} \mathrm{C}$ & $275-283{ }^{\circ} \mathrm{C}$ & $225-232^{\circ} \mathrm{C}$ \\
\hline $\mathrm{pH}$ & 6.40 & 7.01 & 7.21 & 7.79 & 7.98 \\
\hline Viscosity (in cps) & 1.672 & 2.422 & 2.029 & 2.134 & 2.024 \\
\hline Swelling index & 39 & 56 & 79 & 62 & 55 \\
\hline Water Absorption Index & 186 & 262 & 294 & 255 & 240 \\
\hline Total Microbial Load & Absent & Absent & Absent & Absent & Absent \\
\hline Acidity & Non acidified & Non acidified & Non acidified & Non acidified & Non acidified \\
\hline Fluorescence & Nil & Nil & Nil & Nil & Nil \\
\hline Oxidizing Substances & Nil & Nil & Nil & Nil & Nil \\
\hline Sulphated Ash (\%) & 0.09 & 0.08 & 0.06 & 0.04 & 0.10 \\
\hline Loss on Drying (\%) & 3.6 & 3.3 & 2.4 & 6.2 & 4.4 \\
\hline Amylose Content & 5.49 & 4.59 & 18.70 & 13.98 & 11.14 \\
\hline
\end{tabular}

Table 3: Composition of metolazone solid dispersions prepared by a solvent evaporation method $(* 0$ ne part $=10 \mathrm{mg}$ )

\begin{tabular}{ll}
\hline Formulation & Drug: Polymer (Metolazone*: Plasdone K-29/32) \\
\hline MS1 & $1: 0.5$ \\
MS2 & $1: 1.0$ \\
MS3 & $1: 2.0$ \\
MS4 & $1: 3.0$ \\
MS5 & $1: 4.0$ \\
MS6 & $1: 5.0$ \\
\hline
\end{tabular}

Table 4: Physical parameters of metolazone solid dispersions (mean \pm SD; $n=3$ )

\begin{tabular}{llllll}
\hline Solid dispersion & Angle of repose $\mathbf{~}^{\circ}$ ) & Carr's index (\%) & Hausner's ratio & Average particle size ( $\boldsymbol{\mu m})$ & Drug content (mg) \\
\hline MP & 34 & 22 & 1.27 & 45 & $09.54 \pm 1.11$ \\
MS1 & 19 & 1.24 & 185 & $10.02 \pm 1.38$ \\
MS2 & 17 & 1.21 & 176 & $09.98 \pm 1.27$ \\
MS3 & 24 & 15 & 1.19 & 170 & $10.07 \pm 0.97$ \\
MS4 & 22 & 12 & 1.15 & 163 & $10.01 \pm 1.01$ \\
MS5 & 20 & 14 & 1.17 & 172 & $09.87 \pm 0.59$ \\
MS6 & 23 & 15 & 1.18 & $10.11 \pm 1.19$ \\
\hline
\end{tabular}




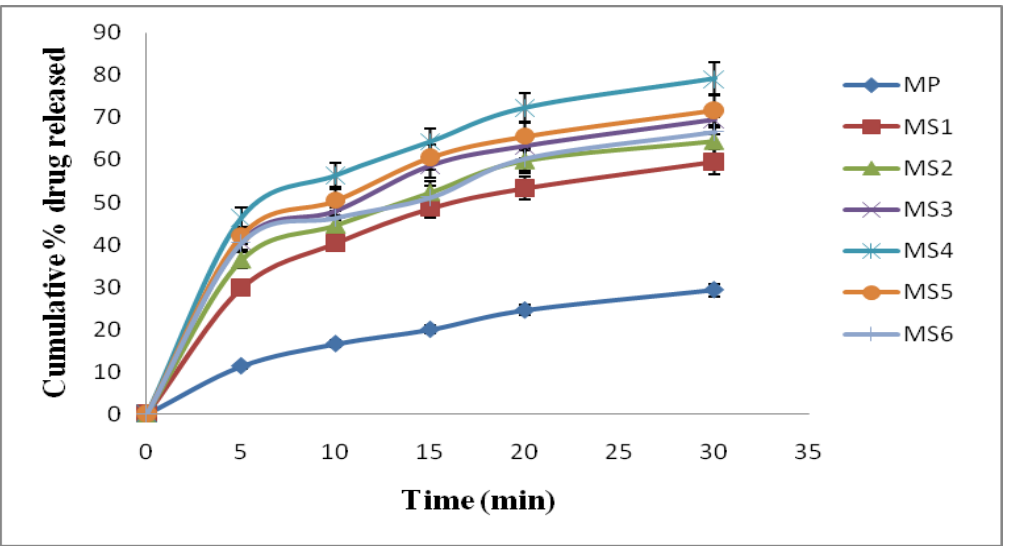

Fig. 1: Drug release profiles of metolazone solid dispersions prepared by a solvent evaporation method $(\operatorname{mean} \pm \mathrm{SD} ; \mathrm{n}=3$ )

\section{Preparation of metolazone tablets}

Metolazone tablets were prepared using the optimized solid dispersions (MS4) along with various concentrations of Sterculia foetida seed starch (SFS2) and croscarmellose sodium (CCS) by direct compression technique. Formulations MPT1 to MPT6 were prepared using 2.5 to $15 \%$ of alkali extracted starch (SFS2). Formulations MPT7 to MPT12 were prepared using 2.5 to $15 \%$ of CCS. The formulation MPD contains only the solid dispersion MS4, but not any of the superdisintegrants. The compositions were given in table 5.

Table 5: Composition of metolazone tablets with different polymer concentrations (Q. S-quantity sufficient)

\begin{tabular}{|c|c|c|c|c|c|c|c|c|c|c|c|c|c|}
\hline \multirow{2}{*}{$\begin{array}{l}\text { Ingredient } \\
\text { (mg/tablet) }\end{array}$} & \multicolumn{13}{|c|}{ Formulations } \\
\hline & MPD & MPT1 & MPT2 & MPT3 & MPT4 & MPT5 & MPT6 & MPT7 & MPT8 & MPT9 & MPT10 & MPT11 & MPT12 \\
\hline $\begin{array}{l}\text { MS4 Solid } \\
\text { Dispersion }\end{array}$ & 40 & 40 & 40 & 40 & 40 & 40 & 40 & 40 & 40 & 40 & 40 & 40 & 40 \\
\hline $\operatorname{MCC}(\mathrm{pH} 102)$ & 202.50 & 196.25 & 190 & 183.75 & 177.50 & 171.25 & 165 & 196.25 & 190 & 183.75 & 177.50 & 171.25 & 165 \\
\hline SFS2 & ---- & 6.25 & 12.50 & 18.75 & 25 & 31.25 & 37.50 & ---- & ----- & ---- & ---- & ---- & ----- \\
\hline CCS & ----- & ----- & ----- & ----- & ----- & ----- & ----- & 6.25 & 12.50 & 18.75 & 25 & 31.25 & 37.50 \\
\hline $\begin{array}{l}\text { Saccharin } \\
\text { Sodium }\end{array}$ & 5 & 5 & 5 & 5 & 5 & 5 & 5 & 5 & 5 & 5 & 5 & 5 & 5 \\
\hline $\begin{array}{l}\text { Pineapple } \\
\text { Flavour }\end{array}$ & Q.S & Q. S & Q.S & Q.S & Q.S & Q.S & Q.S & Q.S & Q.S & Q.S & Q.S & Q.S & Q.S \\
\hline Talc & 1.25 & 1.25 & 1.25 & 1.25 & 1.25 & 1.25 & 1.25 & 1.25 & 1.25 & 1.25 & 1.25 & 1.25 & 1.25 \\
\hline $\begin{array}{l}\text { Magnesium } \\
\text { Stearate }\end{array}$ & 1.25 & 1.25 & 1.25 & 1.25 & 1.25 & 1.25 & 1.25 & 1.25 & 1.25 & 1.25 & 1.25 & 1.25 & 1.25 \\
\hline Total Weight & 250 & 250 & 250 & 250 & 250 & 250 & 250 & 250 & 250 & 250 & 250 & 250 & 250 \\
\hline
\end{tabular}

\section{Evaluation of pre-compression parameters}

The pre compression parameter values obtained for various prepared granules were given in the table 6 . The angle of repose,
Carr's index and Hausner's ratio values for granules were within the range specified. Thus all the prepared granules were found to be stable and suitable for compression of tablets.

Table 6: Pre-compression parameters of granules prepared for tablet formulations

\begin{tabular}{llll}
\hline Formulation & Angle of repose ( $^{\circ}$ ) & Carr's index (\%) & Hausner's ratio \\
\hline MPD & 31 & 21 & 1.22 \\
MPT1 & 27 & 19 & 1.18 \\
MPT2 & 25 & 17 & 1.16 \\
MPT3 & 23 & 16 & 1.15 \\
MPT4 & 23 & 15 & 1.13 \\
MPT5 & 22 & 13 & 1.12 \\
MPT6 & 22 & 12 & 1.12 \\
MPT7 & 28 & 19 & 1.19 \\
MPT8 & 27 & 18 & 1.17 \\
MPT9 & 25 & 16 & 1.15 \\
MPT10 & 24 & 14 & 1.14 \\
MPT11 & 24 & 13 & 1.13 \\
MPT12 & 22 & 12 & 1.12 \\
\hline
\end{tabular}

Evaluation of post compression characteristics of metolazone tablets

The direct compression method was found to be suitable for preparation of fast dissolving tablets. Metolazone tablets were prepared and evaluated for post compression parameters. The results were given in table 7 . Weight uniformity, hardness and friability loss of tablet formulations were within the specified limits and were found to be suitable for further studies. 
Table 7: Post compression parameters of various metolazone tablet formulations (mean $\pm S D ; n=3$ )

\begin{tabular}{|c|c|c|c|c|c|c|}
\hline Formulation & Weight uniformity (mg) & $\begin{array}{l}\text { Hardness } \\
\left(\mathrm{kg} / \mathrm{cm}^{2}\right)\end{array}$ & $\begin{array}{l}\text { Friability } \\
\text { (\% loss) }\end{array}$ & Wetting time (sec) & Dispersion test & $\begin{array}{l}\text { Drug content } \\
\text { (mg/tablet) }\end{array}$ \\
\hline MPD & $250 \pm 1.01$ & $3.9 \pm 0.98$ & 0.4 & 244 & Passed & $10.08 \pm 1.16$ \\
\hline MPT1 & $249 \pm 0.91$ & $3.3 \pm 1.17$ & 0.3 & 84 & Passed & $09.98 \pm 0.68$ \\
\hline MPT2 & $249 \pm 1.11$ & $3.3 \pm 0.85$ & 0.3 & 62 & Passed & $10.05 \pm 1.18$ \\
\hline МРT3 & $250 \pm 1.20$ & $3.2 \pm 1.06$ & 0.2 & 54 & Passed & $10.10 \pm 1.57$ \\
\hline MPT4 & $251 \pm 1.44$ & $3.2 \pm 1.02$ & 0.3 & 33 & Passed & $09.90 \pm 0.82$ \\
\hline MPT5 & $250 \pm 1.32$ & $3.3 \pm 0.75$ & 0.3 & 25 & Passed & $10.05 \pm 0.93$ \\
\hline MPT6 & $249 \pm 0.85$ & $3.2 \pm 1.03$ & 0.2 & 16 & Passed & $10.07 \pm 1.04$ \\
\hline MPT7 & $251 \pm 1.04$ & $3.4 \pm 1.09$ & 0.3 & 90 & Passed & $09.94 \pm 1.37$ \\
\hline MPT8 & $252 \pm 0.98$ & $3.3 \pm 0.94$ & 0.3 & 71 & Passed & $10.18 \pm 1.64$ \\
\hline МРT9 & $251 \pm 1.13$ & $3.3 \pm 0.73$ & 0.2 & 59 & Passed & $10.02 \pm 0.99$ \\
\hline MPT10 & $250 \pm 0.89$ & $3.2 \pm 1.19$ & 0.2 & 40 & Passed & $09.91 \pm 0.77$ \\
\hline MPT11 & $250 \pm 1.51$ & $3.2 \pm 1.35$ & 0.3 & 29 & Passed & $10.18 \pm 1.11$ \\
\hline MPT12 & $250 \pm 0.37$ & $3.2 \pm 1.08$ & 0.3 & 20 & Passed & $10.09 \pm 0.85$ \\
\hline
\end{tabular}

\section{In vitro dissolution studies of metolazone tablets}

Dissolution studies were carried on Metolazone tablets using U. S. P. paddle method (apparatus II) with phosphate buffer $\mathrm{pH} 6.8$ as dissolution medium by maintaining the bath temperature at $37+1^{\circ} \mathrm{C}$ and the paddles were operated at $75 \mathrm{rpm}$. The dissolution profiles of tablets were given in table 8. The study clearly indicated that the concentration of starch as superdisintegrant has highly enhanced the dissolution parameters of the prepared tablet formulations. Formulation MPT6 containing $15 \% \quad \mathrm{w} / \mathrm{w}$ of $\mathrm{SFS} 2$ as superdisintegrant exhibited closer dissolution profile with that of formulation MPT12 prepared by $15 \% \mathrm{w} / \mathrm{w}$ of CCS. Natural superdisintegrant has showed its solubility enhancement efficiency similar to earlier studies $[23,24]$. The superdisintegrant potency of the starch was probably because of the rapid uptake of water, followed by swelling that leads to increase in hydrostatic pressure of tablet that ultimately disintegrates tablets faster [25]. This study thus strongly supports the usage of natural starches as superdisintegrants which was also shown in recent studies [26]. The results were shown in fig. 2 and 3.

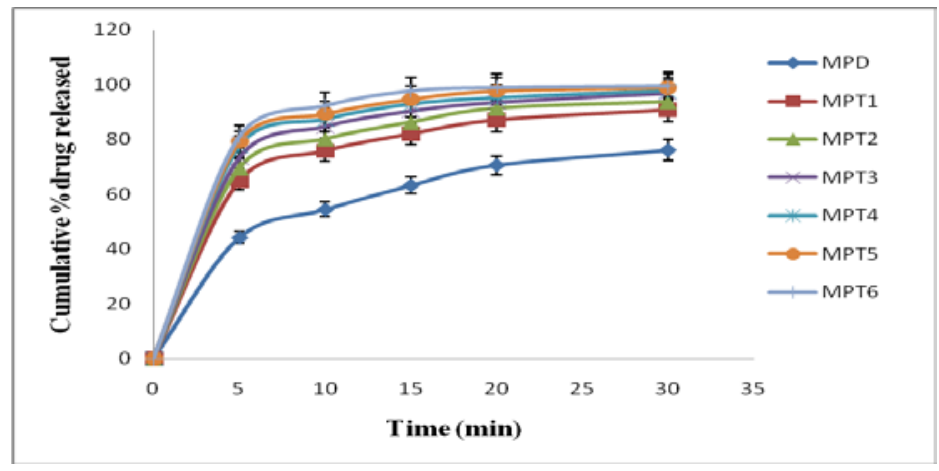

Fig. 2: Dissolution profiles of metolazone tablets prepared by direct compression method (MPT1-MPT6) (mean \pm SD; $n=3$ )

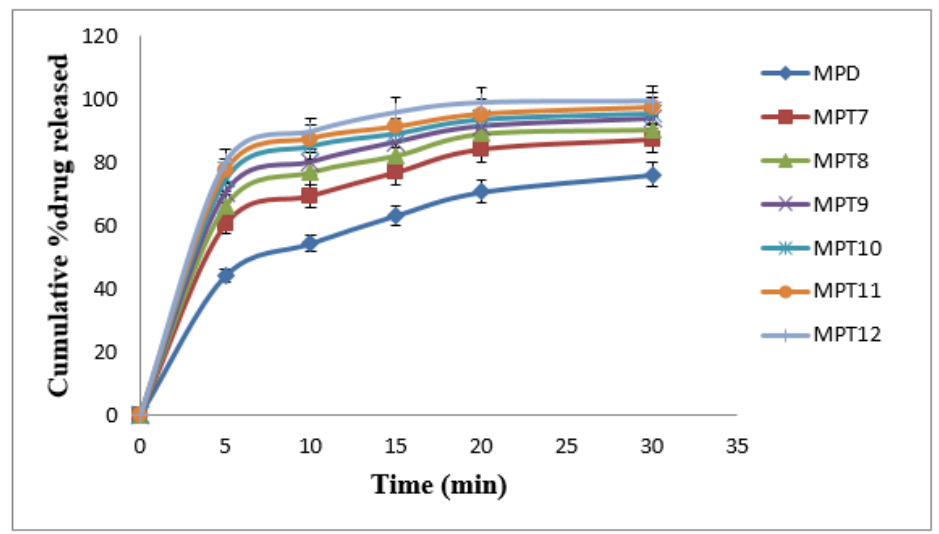

Fig. 3: Dissolution profiles of Metolazone tablets prepared by direct compression method (MPT7 - MPT12) (mean \pm SD; n=3)

\section{Characterization of metolazone fast dissolving tablets}

\section{SEM studies}

Scanning electron microscopy images were taken for Metolazone pure drug, SFS2, CCS, plasdone K-29/32, a blend of Metolazone with plasdone K-29/32, Metolazone with plasdone K-29/32 and SFS2 and Metolazone with plasdone K-29/32 and CCS. Metolazone pure drug exhibited crystalline form. The SFS2 starch exhibited spherical starch grains without any mucilage/resinous coverage. Plasdone K-29-32 exhibited clear granular structure. CCS exhibited blunt tubular shaped crystals. The SEM image of Metolazone with plasdone K-29/32 clearly exhibited uniform mixing of drug with granules. The SEM image of Metolazone with plasdone K-29/32 and SFS2 showed complete dispersion of drug with polymers, whereas Metolazone with plasdone K-29/32 and CCS showed uniform dispersion of drug with blunt tubular crystals of CCS. The detailed SEM images were shown in fig. 4. 


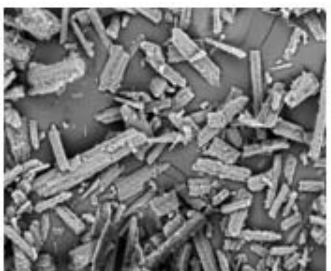

(A)

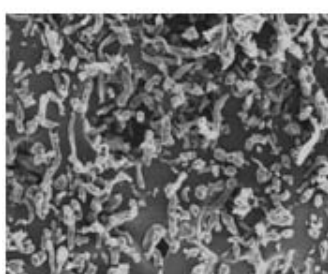

(D)

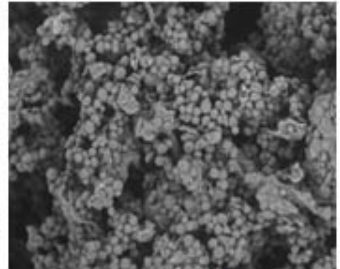

(B)

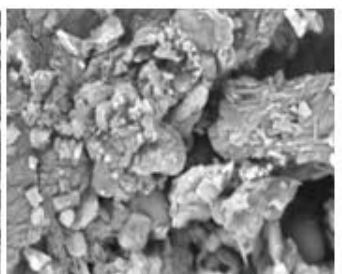

(E)

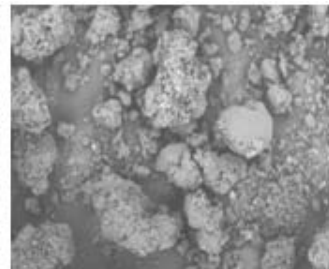

(C)

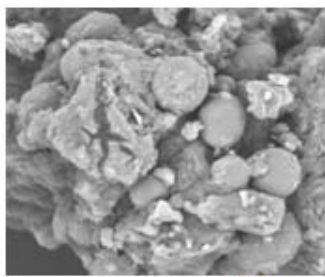

(F)

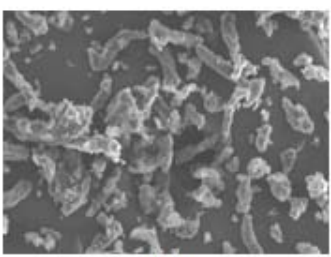

(G)

Fig. 4: SEM images: (A) Metolazone drug (B) SFS2 (C) Plasdone K-29/32 (D) CCS, (E) A blend of Metolazone with plasdone K-29/32 (F) A blend of Metolazone with plasdone K-29/32 and SFS2 (G) A blend of Metolazone with plasdone K-29/32 and CCS SFS2-Sterculia foetida seed starch extracted by $0.1 \%$ sodium hydroxide; CCS-Croscarmellose sodium

\section{Accelerated stability studies of metolazone fast dissolving tablets}

The fast dissolving tablets MPT6 and MPT12 containing Metolazone with MS4 solid dispersion in ratio of 1:3 mixed with SFS2 and CCS in $15 \% \mathrm{w} / \mathrm{w}$ respectively showed good in vitro dissolution and so was subjected to accelerated stability studies. The results were indicated in table 8 .
No visible and physical changes were observed in the fast dissolving tablets after storage. Weight uniformity, hardness, friability, wetting time, dispersion test and drug content were found to be uniform before and after storage at different conditions. It was also observed that there was no significant change in drug release from the FDTs and was indicated in fig. 5 and 6 . Thus the drug release characteristics of FDTs designed were found to be quite stable.

Table 8: Post compression parameters of metolazone fast dissolving tablet formulations (MPT6 and MPT12) under accelerated stability conditions (mean $\pm S D ; n=3$ )

\begin{tabular}{|c|c|c|c|c|c|c|}
\hline Formulation & Storage condition & $\begin{array}{l}\text { Hardness } \\
\left(\mathrm{kg} / \mathrm{cm}^{2}\right)\end{array}$ & $\begin{array}{l}\text { Friability } \\
\text { (\% loss) }\end{array}$ & Dispersion test & $\begin{array}{l}\text { Wetting time } \\
\text { (sec) }\end{array}$ & $\begin{array}{l}\text { Drug content } \\
\text { (mg/tablet) }\end{array}$ \\
\hline \multirow[t]{3}{*}{ MPT6 } & Before Storage & $3.2 \pm 1.03$ & 0.2 & Passed & 16 & $10.07 \pm 1.04$ \\
\hline & $25 \pm 2{ }^{\circ} \mathrm{C}, 60 \pm 5 \% \mathrm{RH}$ & $3.2 \pm 1.37$ & 0.3 & Passed & 17 & $10.05 \pm 1.14$ \\
\hline & $40 \pm 2{ }^{\circ} \mathrm{C}, 75 \pm 5 \% \mathrm{RH}$ & $3.2 \pm 1.18$ & 0.2 & Passed & 17 & $10.06 \pm 1.23$ \\
\hline \multirow[t]{3}{*}{ MPT12 } & Before Storage & $3.2 \pm 1.08$ & 0.3 & Passed & 20 & $10.09 \pm 0.85$ \\
\hline & $25 \pm 2{ }^{\circ} \mathrm{C}, 60 \pm 5 \% \mathrm{RH}$ & $3.3 \pm 1.17$ & 0.3 & Passed & 22 & $10.11 \pm 0.99$ \\
\hline & $40 \pm 2{ }^{\circ} \mathrm{C}, 75 \pm 5 \% \mathrm{RH}$ & $3.2 \pm 1.49$ & 0.3 & Passed & 21 & $10.10 \pm 1.20$ \\
\hline
\end{tabular}

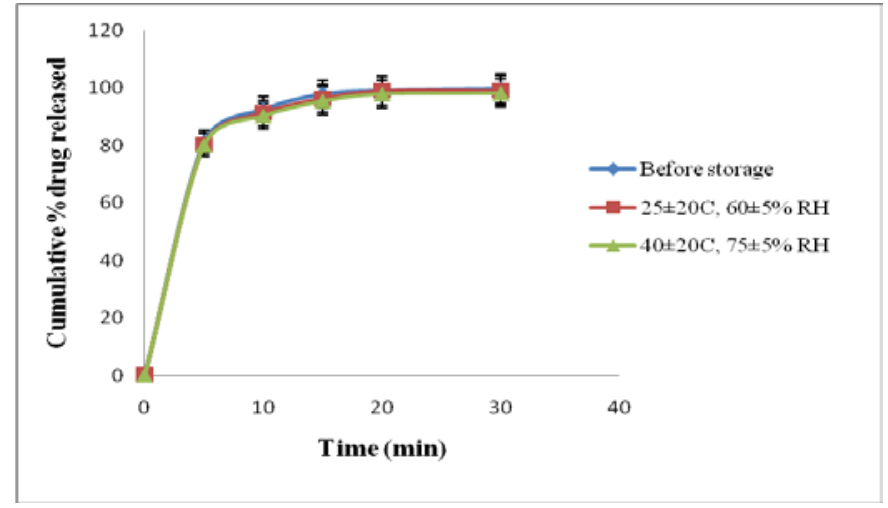

Fig. 5: Dissolution profiles of metolazone fast dissolving tablet formulation (MPT6) before and after storage at different conditions $($ mean \pm SD; $n=3)$ 


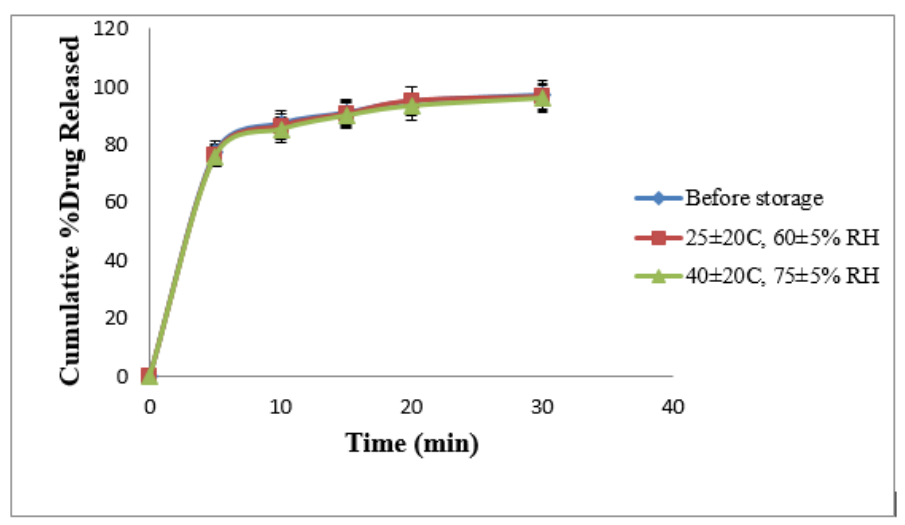

Fig. 6: Dissolution profiles of Metolazone fast dissolving tablet formulation (MPT12) before and after storage at different conditions (mean \pm SD; n=3)

\section{CONCLUSION}

The formulation MPT6 prepared with Metolazone solid dispersions using Plasdone K-29/32 along with Sterculia foetida seed starch $(15 \% \mathrm{w} / \mathrm{w})$ extracted using $0.1 \%$ sodium hydroxide. Similar dissolution profile was observed for formulation, MPT12 containing Metolazone solid dispersion (MS4) along with $15 \% \mathrm{w} / \mathrm{w}$ of CCS. The formulations MPT6 and MPT12 were also found to be stable even when subjected to accelerated stability studies. Based on above studies, it was concluded that Metolazone fast dissolving tablets prepared by Sterculia foetida seed starch extracted from $0.1 \%$ sodium hydroxide showed rapid drug release.

\section{ACKNOWLEDGEMENT}

The authors are thankful to the management of Chebrolu Hanumaiah Institute of Pharmaceutical Sciences for their sheer support throughout the work. The authors also express their thanks to M/s. NATCO Laboratories Ltd., (Hyderabad, India) and Pellets Pharma Ltd., (Hyderabad, India) for their generous gift samples and polymers. The authors are also thankful to Dr. D. Hari Narayana, Nishka Labs, Hyderabad for his extensive support in conducting SEM studies. The authors are also thankful to Acharya Nagarjuna University, Guntur.

\section{FUNDING}

Nil

\section{AUTHORS CONTRIBUTIONS}

Mr. Sandeep doppalapudi the guarantor of this study has designed, carried out the experiment, analyzed the results and contributed in preparation and revision of manuscript. Dr. Vidyadhara Suryadevara has designed, supervised the experimental process and reviewed the manuscript.

\section{CONFLICTS OF INTERESTS}

The authors declare no conflicts of interest

\section{REFERENCES}

1. Khan GM. Controlled release oral dosage forms: some recent advances in matrix type drug delivery systems. J Med Sci 2001;1:350-4.

2. Jin Xi K, Jeong SP, Phuong T, Yong CP, Dong HK, Sang EL. Overview of the manufacturing methods of solid dispersion technology for improving the solubility of poorly water-soluble drugs and application to anticancer drugs. MDPI Pharm 2019;11:1-26.

3. Argade PS, Magar DD, Sudagar RB. Solid dispersion: solubility enhancement technique for poorly water soluble drugs. J Adv Pharm Educ Res 2013;3:427-39.

4. Iswarya S, Abha D, Bhagyashri J, Vandana W, Jesal D. Solid dispersions: an approach to enhance solubility of poorly water soluble drug. J Sci Innovative Res 2013;2:685-94.
5. Garima Y, Anupriya K, Shilpi B. Fast dissolving tablets recent advantages: a review. Int J Pharm Sci Res 2012;3:728-36.

6. Mohanachandran PS, Sindhumol PG, Kiran TS, Superdisintegrants: an overview. Int J Pharm Sci Rev Res 2011;6:105-9.

7. Kusum K, Ram BS, Shweta A. Natural polymers and their applications. Int J Pharm Sci Rev Res 2016;37:30-6.

8. Rajeswari S, Prasanthi T, Navya S, Ranjit PS, Satyajit P, Vinusha G. Natural polymers: a recent review. World J Pharm Pharm Sci 2017;6:472-94.

9. Swarnalatha K, Venkata KB, Hari BB. Phytochemical screening, anti-diabetic and antioxidant activities of Kigelia Africana (LAM.) and Sterculia foetida L. Rasayan J Chem 2019;12:907-14.

10. Xueqing Li, Rutao W, Yang L, Yun L, Heng Z, Yabo F. Pharmacokinetic study of single-and multiple-dosing with metolazone tablets in healthy Chinese population. BMC Pharmacol Toxicol 2017;18:1-10.

11. Vidyadhara S, Sasidhar RL, Lakshmi HD, Vijetha P, Vijetha K. Studies on jack fruit seed starch as a novel natural superdisintegrant for the design and evaluation of Irbesartan fast-dissolving tablets. Integr Med Res 2017;6:280-91.

12. Rubina NS, Mubeen MA, Kiran N, Vijay P, Asma BS, Imad UM. Phytochemcial screening and in vitro anti-inflammatory activity of methanolic extract of Sterculia foetida L. IOSR J Pharm Biol Sci 2016;11:28-34.

13. Sundeep M, Vidyadhara S, Sailaja Y, Sandeep D, Sasidhar RL, Ramu A. Formulation and evaluation of dolutegravir sodium solid dispersions and fast dissolving tablets using poloxamer188 and jack fruit seed starch as excipients. Asian J Pharm Clin Res 2019;12:1-10.

14. Prashant B, Reeshwa N. Formulation, development and characterization of Meclizine hydrochloride fast dissolving tablets using solid dispersion technique. Int J Appl Pharm 2018;10:141-6.

15. Pinak K, Mansi S, Niketkumar P, Shashank J, Namrata V, Senshang L. Preparation and characterization of pyrimethamine solid dispersions and an evaluation of the physical nature of pyrimethamine in solid dispersions. J Drug Delivery Sci Tech 2018;45:110-23.

16. Vikaas B, Ritika MB, Sandeep K, Nitesh C, Manjusha C. Formulation and evaluation of fast disintegrating tablet of telmisartan. J Chem Pharm Res 2016;8:61-7.

17. Manimaran V, Damodharan N. Development of fast dissolving tablets of nisoldipine by solid dispersion technology using poloxamer 407 and poloxamer 188. J Young Pharm 2016;8:341-9.

18. Mahmoud EM, Mahmoud MA, Khalid AK, Hatem AS. Accelerated physical stability testing of tolmetin sodium fast dissolving tablets prepared by direct compression method. Int J Pharm Pharm Res 2017;8:42-51.

19. Bhairav BA, Jagtap LR, Saudagar RB. Solubility and dissolution enhancement of pioglitazone using solid dispersion technique. Int J Curr Pharm Res 2017;9:186-93. 
20. Shirsath NR, Jagtap V, Goswami AK. Formulation and development of Famotidine solid dispersion tablets for their solubility enhancement. Indian J Pharm Educ Res 2019;53:54853.

21. Pinak K, Mansi S, Niketkumar P, Shashank J, Namrata V, Senshang L. Preparation and characterization of pyrimethamine solid dispersions and an evaluation of the physical nature of pyrimethamine in solid dispersions. J Drug Delivery Sci Tech 2018;45:110-23.

22. Gagandeep S, Navjot S, Randeep K, Neena B. Development and characterization of nevirapine loaded amorphous solid dispersions for solubility enhancement. Asian J Pharm Clin Res 2019;12:176-82.
23. Uday KM, Kishore BM. Design and evaluation of fast dissolving tablets containing diclofenac sodium using fenugreek gum as a natural superdisintegrant. Asian Pac J Trop Biomed 2014;4:329-34.

24. Emmanuel 00, Musiliu OA, Ekaete IA. Evaluation of callinectes chitosan as a superdisintegrant in metronidazole tablet. Int J Pharm Pharm Sci 2017;9:111-8.

25. Sanjaymitra PS, Ganesh GN. Dissolution and solubility enhancement strategies: current and novel prospectives. J Crit Rev 2018;5:1-10.

26. Madaan R, Bala R, Vasisht T, Sharma R, Garg S. Formulation and characterization of matrix tablets using mucilage of Tinospora cordifolia as natural binder. Int J Pharm Pharm Sci 2018;10:22-7. 